\title{
The importance of lifestyle changes in patients with uncontrolled asthma
}

\author{
Yelda VAROL ${ }^{1}$ \\ Umut VAROL ${ }^{2}$ \\ Özgür BATUM ${ }^{1}$
}

\author{
${ }^{1}$ Clinic of Chest Diseases, Dr. Suat Seren Chest Diseases and Surgery Training \\ and Research Hospital, Izmir, Turkey \\ ${ }^{1}$ Dr. Suat Seren Göğüs Hastalıkları ve Cerrahisi Eğitim ve \\ Araştırma Hastanesi, Göğüs Hastalıkları, İzmir, Türkiye \\ ${ }^{2}$ Clinic of Medical Oncology, Izmir Katip Celebi University Ataturk Training \\ and Research Hospital, Izmir, Turkey \\ ${ }^{2}$ Izmir Katip Çelebi Üniversitesi Atatürk Eğitim ve Araştırma Hastanesi, Tıbbi \\ Onkoloji Kliniği, İzmir, Türkiye
}

A 24 year-old male patient with asthma who was using long acting $B_{2}$ agonists and high dose inhaled steroids was regularly attending toan outpatient pulmonary clinic. He has high body weight (BMI $28.4 \mathrm{~kg} / \mathrm{m}^{2}$ ) and a sedentary lifestyle. He was very anxious because of using high dose of steroids for a long period of time and psychosocial factors about job stress leading to a bad sleep quality. He also had pollen allergy proven by skin allergy prick test and environmental exposure to these seasonal allergens contributed to trigger his asthma attacks and increased his attacks' frequency and severity. One way was to add-on treatment and to step up medication for symptom control, but he did not want to use more drugs. In order to improve his lung functions; he has changed his daily life physical activity andlost weight for achieving ideal body composition. He alsomoved house to minimize exposing to outdoor pollens, changed his working methods for dealing with job stress and modified his lifestyle to reduce the stress in his life. After a period of time, his dyspnea and other asthma related symptoms were reduced, usage of rescue medication and inhaled steroid dosage were decreased.

Asthma is closely related to the changes in lifestyle of the patient. Environmental and personal factors are in close relation of the severity of the disease (1). Clinical studies have showed that obese asthmatics have worse clinical control and increase in body weight maydeteriorate the symptoms despite an optimized medical treatment (2). The correlation between bronchial asthma and sedentary life was also determined both as a predisposing factor for this disease and as a worsening factor for the patients under treatment. There is a substantial body of evidence on the efficacy of physical activity in the management of bronchial asthma with some of the studies have reported significant increase in pulmonary functions and reduction in airway hyper-reactivity, frequency of attacks and medication use (3). Besides, current data suggests an opposite association between chronic psychosocial stress and asthma morbiditywhich may impactcontrol of the disease and overall quality of life in asthmatic patients (4).

\section{Yazışma Adresi (Address for Correspondence)}

Dr. Umut VAROL

İzmir Katip Çelebi Üniversitesi Atatürk Eğitim ve Araştırma Hastanesi, Tıbbi Onkoloji Kliniği, IZMiR - TURKEY

e-mail: varolumut@yahoo.com 
Bronchial asthma has an inflammatory related nature and the potential mechanism of benefit of these lifestyle changes can be explained in lung mechanical and airway inflammation. For example, obesity results in important changes in the mechanical properties of the respiratory system including chronic systemic inflammation, and endocrine factors which could explain as one of the underlying mechanismof asthma (5). Additionally exercise is a very powerful bronchodilator stimulus in both normal subjects and asthmatic patients, and even symptomatic patients with insufficiently controlled asthma showed bronchodilation during exercise, with preserved oxygen consumption and maximal ventilation (3). High physiologic stress levels were also shown to cause reduced bronchodilator response as a result of behavioral, autonomic, and immunologic responses to stress (4). Pokladnikova et al. evaluated the effectiveness of a comprehensive lifestyle modification program for asthma patients and observed significant stress reduction and greater psychosocial and spiritual wellbeing in the intervention group (6).

We 'the physicians' know that lifestyle changes are very important in disease control. However, do we always give the essential care for changing the patients' lifestyle? Or are we spending enough time to explain how important it is? So, identifying preventable or treatable risk factors in patients with asthma needs to be determined in every stage of the treatment and patients have to be encouraged to change their lifestyle (7). As a result, modifications in life habits of the patients should be an integrated part of asthma management and taking all actions reducing aggravating factors may improve their clinical control significantly and offer greater clinical benefit than standard care alone.

\section{REFERENCES}

1. Nogueira KT, Silva JR, Lopes CS. Quality of life of asthmatic adolescents: assessment of asthma severity, comorbidity, and life style. J Pediatr (Rio J) 2009;85:523-30.

2. Freitas $P D$, Ferreira $P G$, da Silva $A$, Trecco $S$, Stelmach $R$, Cukier $A$, et al. The effects of exercise training in a weight loss lifestyle intervention on asthma control, quality of life and psychosocial symptoms in adult obese asthmatics: protocol of a randomized controlled trial. BMC Pulm Med 2015;15:124.

3. Mancuso CA, Choi TN, Westermann H, Wenderoth S, Wells MT, Charlson ME. Improvement in asthma quality of life in patients enrolled in a prospective study to increase lifestyle physical activity. I Asthma 2013;50:103-7.

4. Rosenberg SL, Miller GE, Brehm JM, Celedón JC. Stress and asthma: novel insights on genetic, epigenetic, and immunologic mechanisms. J Allergy Clin Immunol 2014;134:1009-15.

5. Pakhale S, Baron J, Dent R, Vandemheen K, Aaron SD. Effects of weight loss on airway responsiveness in obese adults with asthma: does weight loss lead to reversibility of asthma? Chest 2015;147:1582-90.

6. Pokladnikova J, Selke-Krulichova I. Effectiveness of a comprehensive lifestyle modification program for asthma patients: a randomized controlled pilot trial. J Asthma 2013;50:318-26.

7. Sybilski AJ, Lusawa A, Lipiec A, Piekarska B, Raciborski F, Krzych-Fatta $E$, et al. The effects of disease awareness on lifestyle changes and the use of preventive measures in asthma patients. Allergy Asthma Proc 2015;36:e14-22. 